\title{
Uso de jogos lúdicos no processo de ensino-aprendizagem nas aulas de Química
}

\author{
João Ricardo Souza do Rêgo ${ }^{1}$, Felipe Magno da Cruz Junior ${ }^{2}$ e \\ Maria Gabriella da Silva Araújo ${ }^{3}$
}

\footnotetext{
1 Mestrando do Programa de Pós-Graduação em Recursos Hídricos, Universidade Federal do Pará, Especialização em Educação Especial pela Faculdade Integrada Ipiranga e Graduado em Química pela Universidade estadual do Maranhão, Brasil. E-mail: ricardorego@ufpa.br.

2 Especialização em Metodologia do Ensino de Biologia e Química pela Uninter e Graduado em Química pela Universidade Estadual do Maranhão, Brasil. E-mail: felipemag71@hotmail.com

3 Graduada em Engenharia Ambiental e Energias Renováveis pela Universidade Federal Rural da Amazônia, Brasil. E-mail: ma.gabriella_araujo@live.com
}

RESUMO: O uso de jogos lúdicos no processo de ensino-aprendizagem nas aulas de química é uma maneira encontrada pelos professores para que o ensino de torne didático no cotidiano dos alunos. Assim, este artigo tem uma breve discussão sobre qual o conceito de jogos lúdicos, e de que maneira esses jogos podem influenciar no cotidiano da aprendizagem do ensino de Química, feita através de um questionário estruturado, apresentado e respondido por alunos do $9^{\circ}$ ano do Colégio São Paulo, localizado no município de Belém, Estado do Pará. Como metodologia foi usada questionário estruturado de caráter objetivo para melhor compreensão da visão dos alunos quanto as práticas de jogos como modelo de ensino de química. Conclui-se que a utilização de jogos didáticos é um instrumento de ensino que facilita a aprendizagem por despertar o interesse do educando e motivá-lo a aprender de forma mais prazerosa. Os resultados obtidos sugerem que os jogos educacionais atuam como ferramentas eficientes nos processos de ensino e aprendizagem da Química.

Palavras-chave: Alunos, Ensino fundamental, Didática.

\section{Use of playful games in the teaching-learning process in Chemistry classes}

ABSTRACT: The use of playful games in the process of teaching learning in chemistry classes is a way found by teachers so that teaching becomes pedagogical in the daily life of students. Thus, this article has a brief discussion about the concept of playful games, and how these games can influence the daily learning of teaching chemistry, made through a structured questionnaire, presented and answered by students of the $9^{\circ}$ year of the college São Paulo, situated in Belém, State of Pará. As a methodology was used a structured questionnaire of objective character to better understands the students' vision regarding the practice of games as a model of teaching of chemistry. It is concluded that the use of teaching games is a teaching tool that facilitates learning by arousing the student's interest and motivating him to learn in more pleasurable way. The results obtaines suggest that educational games act as efficient tools in the teaching and learning process of chemistry.

Keywords: Students, Elementary school, Teaching.

\section{INTRODUÇÃO}

Lúdico tem sua origem no latim ludus que se refere a divertimento e jogos. Com o objetivo de dar prazer e divertimento para aqueles que estão participando, uma atividade lúdica é caracterizada por ser espontânea, satisfatória e funcional, mas sempre almejando o aprendizado, pois potencializam a criatividade e o desenvolvimento in- 


\section{0}

telectual dos alunos. Assim como diz Marcelino (1996, p.38)

É fundamental que se assegure à criança o tempo e os espaços para que o caráter lúdico do lazer seja vivenciado com intensidade capaz de formar a base sólida para a criatividade e a participação cultural e, sobretudo para o exercício do prazer de viver, e viver, como diz a canção... como se fora brincadeira de roda.

Sendo assim a atividade lúdica deve proporcionar à criança o prazer de participar da atividade, as brincadeiras são necessárias, pois através delas o aluno consegue absorver um determinado assunto de maneira mais fácil. A brincadeira deve ter um direcionamento e um propósito, visto que a realização desta não é apenas para desgastar energia, mas para o desenvolvimento das capacidades cognitivas e corporais. Desta forma, o professor precisa reconhecer a importância da prática destas atividades para que estas se tornem mais um instrumento facilitador do processo de ensinoaprendizagem, pelo fato de possibilitar a ressignificação para os conteúdos, além de promover a incitação de atitudes positivas e saudáveis dentro do âmbito escolar (PIAGET, 1993).

As atividades devem levar também ao desenvolvimento da imaginação, pois isso possibilita ao aluno a promoção de sua criatividade e das suas capacidades cognitivas, Freire (1997, p. 46) explica que:

A criança faz uso da imaginação, vive e encarna um sem número de relações. Saltar um rio largo, atravessar uma ponte estreita, repartir a comida feita, são atividades que materializam, na prática, a fantasia imaginada, e que retornarão depois da prática em forma de ação interiorizada, produzindo e modificando conceitos, incorporando-se às estruturas de pensamento. Ou seja, no brinquedo simbólico a ação vai e vem incessantemente, da ação ao pensamento, modificando-se em cada trajeto, até que as representações do indivíduo possam se expressar de forma cada vez mais compreensível no universo social. A prática social não interrompe, contudo, esse jogo de idas e vindas da ação e da representação, pelo contrário, sofistica cada vez mais as representações que o sujeito faz do mundo.

Através da imaginação e da prática de certas atividades o aluno irá interiorizar o que aprendeu e modificará conceitos, possibilitando a aprendizagem. Este não é um simples passatempo, o jogo é essencial e deve ter um planejamento, pois através dele o aluno pode utilizar todas as suas potencialidades de maneira integral.

Portanto, devido a esta série de benefícios que as atividades lúdicas exercem na vida de uma criança que se ressalta a importância da sua aplicação pelo professor dentro da sala de aula, seguindo um proposito de facilitar o ensino de determinada disciplina e instigar a compreensão do conteúdo por parte do aluno através do seu maior envolvimento com o jogo. O professor ao adotar a ludicidade em suas aulas as torna interessante e chamariam mais a atenção dos alunos ao que está sendo ministrado, pois seria uma forma mais agradável de ensinar (BERTOSO; MOTA, 2011).

Para a utilização de cada jogo o professor tem que ter em mente os objetivos daquele jogo. A participação do professor é necessária para que o objetivo possa ser alcançado. Então a ludicidade é essencial para ser utilizada na sala de aula, pois através dela o 
aluno compreenderá melhor as disciplinas ensinadas e possibilitaria assim uma aula mais envolvente e muito mais interessante. Dessa forma o aluno terá a oportunidade de desenvolver capacidades que são indispensáveis como a afetividade e de concentração, até mesmo habilidades psicomotoras formando um indivíduo que tenha suas capacidades afetivas, cognitivas e motoras, tornando-o mais crítico.

Portanto, este estudo objetiva avaliar como a prática de jogos lúdicos durante as aulas podem influenciar no aprendizado de um grupo de alunos da disciplina de química de uma escola de ensino fundamental.

\section{REFERENCIAL TEÓRICO}

A palavra jogo vem do latim jocu que significa "gracejo" e para Fin (2006) o jogo envolve competição entre os participantes, bem como regras que devem ser observadas por eles. Na Educação a palavra jogo é sinônima de estímulo ao crescimento cognitivo do aluno.

A cultura dos jogos lúdicos é um conjunto de procedimentos que permite tornar o jogo viável, transformando o conhecimento empírico em criticidade nos alunos, o que propicia um desenvolvimento cognitivo, afetivo e moral. O mais simples dos jogos possibilita grandes benefícios àqueles que se comprometem a fazer parte da interação proporcionada pela atividade desenvolvida, assim, autoconfiança, destreza e competência, são algumas das muitas habilidades aprimoradas nas interações proporcionadas durante os jogos (FERNANDES et al., 1995).

Os jogos lúdicos influenciam o desenvolvimento da criança. Através do jogo a criança aprende a agir, pois tem sua curiosidade estimulada, além de obter iniciativa e auto- confiança, o que transforma o desenvolvimento do pensamento e da concentração (VYGOTSKY, 1989). Trabalhar com algo que se gosta, que desafia e que "tende" a um bom resultado exige atenção e esta virá como consequência deste envolvimento.

Os jogos interativos servem para ensinar e educar e se constituem como ferramentas instrucionais eficientes. Cabe ao docente organizar as atividades de ensino utilizando os recursos para criar as condições ideais para que os alunos dominem os conteúdos, desenvolvam a iniciativa, a curiosidade científica, a atenção, a disciplina, o interesse, a independência e a criatividade.

Os jogos estimulam a criação de estratégias de resolução de problemas apresentados durante o jogo lúdico o que expande o desenvolvimento cognitivo e o senso critico do aluno. Tornando o saber mais usual ao aluno (FREIRE, 1997).

Para Vygotsky (1989) o jogo tem importância por influência no desenvolvimento da concentração, e através do jogo o aluno é levado a uma esfera de conhecimento no qual se vê em uma situação, influenciando na sua criticidade e seu discernimento em diversas situações.

É necessário então que o educador entenda os anseios das crianças para compreender a importância do lúdico, quando tiver feito isso terá uma tarefa muito mais difícil que é o de associar o lúdico ao conteúdo a ser ministrado, sem que os dois percam suas essências sendo sacrificado o menos possível. Mas quando há o equilíbrio entre as duas funções consegue-se o jogo educativo (SCHWARTZ, 1998, p.36).

Então, o aluno participa com o objetivo de obter prazer. Para os adultos que dese- 
jam usar o jogo com objetivos educacionais, este é visto como um caminho no qual sua tarefa é escolher qual o jogo adequado, o veículo adequado, para transmitir a mensagem educacional desejada.

O ensino da química ao envolver a transmissão/aquisição de conhecimentos relativos aos elementos e compostos químicos (características, configurações, propriedades e entre outras informações), em muitos casos, dependendo da forma didática como o ensino é conduzido em sala de aula pelo professor, é considerada uma disciplina maçante, pois envolve em seu conteúdo programático uma diversidade de símbolos, nomenclaturas, fórmulas e cálculos que dificultam a aprendizagem do assunto por alguns alunos e consequentemente, aumenta os desafios do educador em tornar o ensino mais atrativo (FERREIRA et al., 2012).

De forma geral, a utilização de jogos é um importante recurso didático por proporcionar uma metodologia diferenciada na relação ensino-aprendizagem. No caso da química, eles proporcionam uma experiência prática ao abordar conhecimentos em contextos específicos e a familiarização da linguagem química, ampliando no educando as suas habilidades e capacidade de compreender conceitos. Contudo, é importante ressaltar que estas atividades não devem ser utilizadas com o objetivo de memorização do conteúdo ministrado (CUNHA, 2012).

\section{METODOLOGIA}

O estudo foi desenvolvido com 69 alunos que compõem duas turmas do $9^{\circ}$ ano do Colégio São Paulo, localizado no município de Belém do Pará, sendo sua execução divi- da em dois momentos. Primeiramente a apresentação do jogo de reação química a estes alunos e posteriormente a aplicação de um questionário semi-estruturado aos mesmos.

O Jogo das Reações é constituído por 18 fichas contendo as substâncias reagentes e 18 fichas contendo as substâncias produtos de reações. As fichas devem ter cores diferentes para definir uma cor para reagentes e outra para o produto. 0 jogo foi estruturado para reações inorgânicas mais comuns. O objetivo é associar os reagentes de uma reação química aos seus respectivos produtos. O conhecimento exigido é referente ao conteúdo de reações químicas e nomes dos compostos. Para melhor execução da atividade, são utilizados quatro jogadores por grupo tendo um tempo médio de duração de 50 minutos cada jogo (Figura 1).

Figura 1. Grupos de alunos para a realização do Jogo das Reações.

Figure 1. Groups of students to perform the Reaction Game

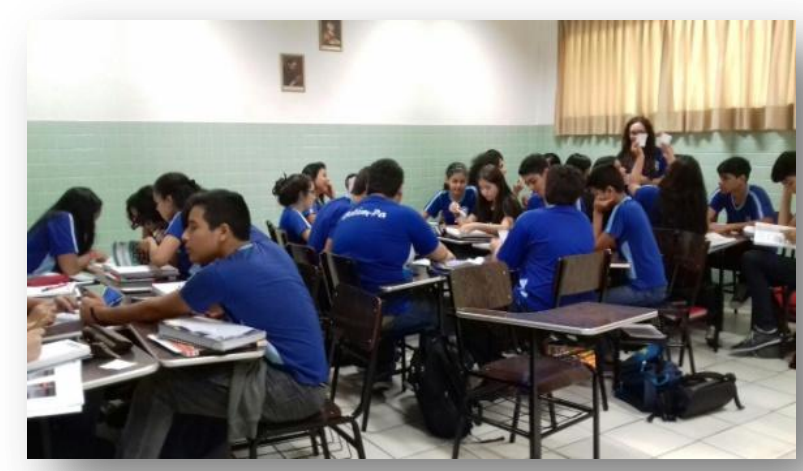

Fonte: Os autores

As regras do jogo são:

1) Distribuir os alunos em grupos com 4 componentes;

2) Cada grupo deve receber fichas, que representam as substâncias reagentes e produtos de reações químicas, que são expostas em suas mesas para que possam 
visualizar a combinação das substâncias que participam da reação química e a formação do produto;

3) É necessário que os participantes verifiquem quais fichas se encaixam às substâncias reagentes que formam novas substâncias após reagirem. O aluno que conseguir montar a reação completa deve reter as fichas e dar a vez para o próximo praticar a brincadeira das reações. Caso o aluno sinta dificuldade para encontrar o produto da reação, o mesmo deverá liberar as fichas e deixar outro aluno participar do jogo;

4) Vencerá o aluno que adquirir o maior número de fichas com a formação de reação completa.

Quanto ao questionário, foram feitas perguntas objetivas que permitia que o aluno acrescentasse sua opinião sobre o assunto. Essas perguntas buscam de forma mais clara e compreensiva entender a visão do aluno sobre uso de jogos lúdicos na sala de aula, as quais foram: 1) Você gosta de estudar química? Justifique; 2) Seu professor usa jogos ou atividades diferenciadas nas aulas de Química?; 3) O uso de jogos e atividades lúdicas ajuda na sua aprendizagem da disciplina Química?; 4) Sobre a utilização do jogo das reações químicas, você achou uma boa ferramenta para ajudar na assimilação do conteúdo?; 5) Durante o jogo, você: a) Foi participativo querendo aprender; b) Participou apenas por diversão; c) Participou apenas por causa da avaliação continua (Atividades trabalhadas em sala) de 2 pontos; 6) Após o jogo das reações químicas, você se sentiria seguro em responder exercícios de fixação do assunto abordado?; 7) Seu professor de Química explica bem os conteúdos? 8) Quando o professor planeja um jogo, você prefere que seja jogado em equipe ou individual- mente? Justifique a sua resposta; 9) Dê a sugestão de quatro jogos que você gostaria que fossem jogados para assimilar outros conteúdos de química.

\section{RESULTADOS E DISCUSSÃO}

Vários estudos e pesquisas mostram que o Ensino de Química é geralmente tradicional, centralizando-se na simples memorização e repetição de nomes, fórmulas e cálculos, totalmente desvinculados do dia-a-dia e da realidade em que os alunos se encontram. O uso da educação bancária, descrita por Paulo Freire (1996), relata a dificuldade do processo de ensino-aprendizagem na sala de aula. A educação bancária consiste em uma atitude autoritária e opressiva por parte do detentor do conhecimento transformando aquele que recebe em apenas passivo e receptivo ao saber, tornando-o depósito de informações.

É preciso insistir: este saber necessário ao professor - que ensinar não é transferir conhecimento - não apenas precisa ser apreendido por ele e pelos educandos nas suas razoes de ser - ontológica, política, ética, epistemológica, pedagógica, mas também precisa ser constantemente testemunhado, vivido (FREIRE, 1996, P.27).

É necessária a compreensão por parte dos docentes e dos discentes que o processo de ensino-aprendizagem não poder ser autoritário, mas uma interação entre o conhecimento do aluno e do professor para a construção da criticidade na sala de aula. É desta relação que surge a importância do uso dos jogos lúdicos, para que o aluno perceba que o conhecimento não é algo rígido 
e com normas invioláveis, mas um processo gradativo de aprendizado através de ferramentas utilizadas no seu cotidiano.

Sendo assim, os alunos do Colégio São Paulo, foram questionados se gostavam de estudar química e se achava interessante o conteúdo abordado, $60 \%$ deles descreveram o ensino dizendo se sentir estimulado a conhecer a química do cotidiano, as substâncias, as misturas e as reações químicas que ocorrem na natureza. Já $40 \%$ sentem dificuldades em assimilar alguns assuntos abordados. Justificam ainda a importância da prática de aulas experimentais, jogos lúdicos e excursões pedagógicas para facilitar a aprendizagem. Já os que responderam que não gostam de estudar química, atribuíram dificuldades em compreender e assimilar alguns conteúdos da disciplina.

Quando perguntados se o professor usava de jogos e/ou atividades diferenciadas nas aulas de química, $100 \%$ dos alunos responderam que sim, que eram utilizados esses métodos para facilitar o ensino do conteúdo. Por possuir conteúdos sobre fórmulas e cálculos que muitas vezes não são associados ao cotidiano dos alunos, muitas vezes o ensino da química se torna maçante e monótono, para uma melhor compreensão dos assuntos, é necessário que a realidade do aluno esteja inserida no contexto, ou que objetos próximos possam fazer parte do ensino. Para isso os alunos foram questionados se o uso de jogos lúdicos ajudava na aprendizagem da disciplina de química, sendo as respostas apresentadas no Gráfico 1.
Gráfico 1. Contribuição de jogos lúdicos no processo de ensino aprendizagem.

Graphic 1.Contribution of playful games in the process of teaching learning.

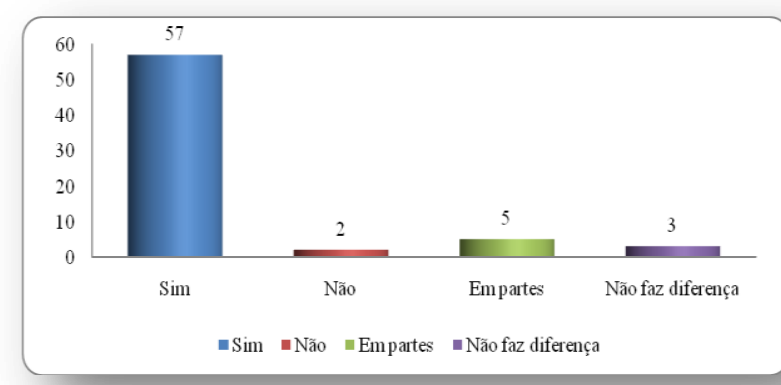

Fonte: os autores

A utilização de atividades lúdicas no ensino de Química está ligada a busca por meIhorias no processo de ensino e aprendizagem. Diante disso, a construção de jogos didáticos para o ensino de Química se configura como uma das inúmeras alternativas viáveis para a promoção de tais melhorias. Estes jogos estão sendo vistos como um grande recurso auxiliar para o processo ensino-aprendizagem das Ciências. Esses recursos podem ser capazes de dinamizar as aulas ao ponto de incentivar interesse e motivação, que são aspectos necessários para favorecer um aprendizado mais eficiente perante o ensino de conceitos.

Sendo assim, a abordagem construtivista favorece os jogos lúdicos e a descoberta individual, a construção do saber não é determinada pela velocidade que ele absorve conhecimento, mas sim construído gradativamente pela interação do individuo com o meio físico e social divergindo do tradicional em que o aluno é um deposito e o professor meramente um mediador de informações.

Quanto a assimilação do conteúdo de reações químicas, 61 alunos disseram que o jogo foi uma boa ferramenta para a compreensão do conteúdo, apenas 2 disseram 
que não foi bom e 4 disseram que em partes o jogo foi facilitador da assimilação do conteúdo (Gráfico 2).

Grafico2. Resposta dos alunos quanto assimilação do conteúdo de reações químicas através do jogo das reações.

Graphic2. Students' responses to assimilating the content of chemical reactions through the play of reactions.

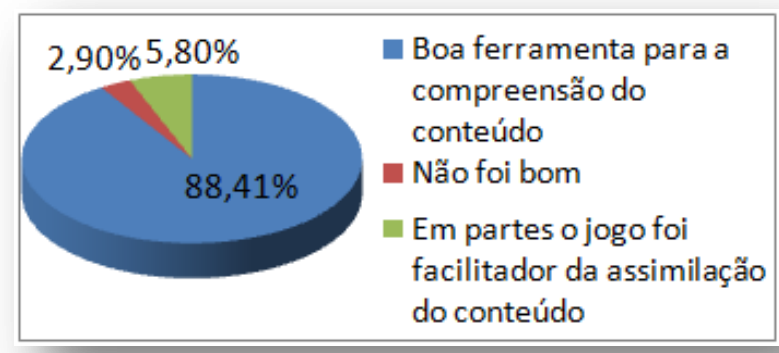

Fonte: os autores

Para Vigotsky (2007), o jogo (ou brinquedo como ele se refere) é um instrumento que possibilita a criança a agir "numa esfera cognitiva". Sendo assim, quando perguntados qual a intenção do aluno de participar do jogo das reações, obteve-se que 50\% dos alunos participaram apenas por interesse, o que mostra que para este o jogo das reações químicas ainda foi visto pelos alunos apenas como mais um "trabalho" da escola, processo de avaliação continuada; $42 \%$ estavam interessados em aprender e desenvolver a atividade e apenas $8 \%$ viu a atividade como meio de diversão (gráfico 3).

Gráfico 3: Avaliação dos alunos quanto seus interesses Graph 3: Students evaluation about your interesting

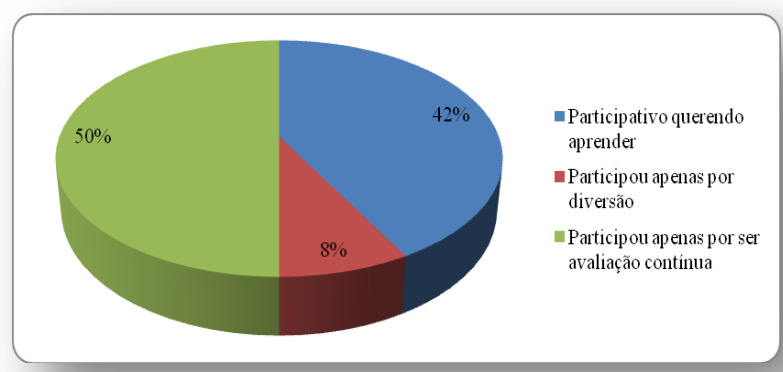

Fonte: Os autores
É importante que se compreenda que os jogos não contribuem apenas para a diversão do aluno, mas também para o desenvolvimento cognitivo dos indivíduos. Nem tão pouco a ludicidade pode ser utilizada como uma ferramenta exclusiva de aprendizado. Tanto os jogos como as metas educativas deverão estar em equilíbrio.

Os alunos foram questionados se após o jogo de reações químicas se sentiriam seguros de responder exercícios de fixação do assunto abordado, 42 alunos, o que significa uma boa parcela deles $(60,87 \%)$, responderam que sim, que estavam preparados para responder ao exercício de fixação; 20 (28,99\%) disseram que conseguiram responder em partes, e apenas $5(7,25 \%)$ alunos disseram que não conseguiriam responder.

Foram questionados ainda se o professor de química explicava bem o conteúdo, 42 dos alunos disseram que sim, que o conteúdo é bem explicado na sala de aula, 20 disseram que em partes e 5 disseram que não.

É importante compreender que o professor não pode se limitar a um facilitador na medida em que se tem a responsabilidade de ensinar, porque é função do professor fazer com que seus alunos aprendam conteúdos específicos dos programas e currículos escolares. É fundamental que o professor organize os dados de modo eficaz, pois os alunos precisam ter acesso aos conteúdos de aprendizagem (NAMO DE MELO, 1994).

A nona pergunta se refere a sugestão de 4 jogos que os alunos gostariam que fossem realizados para ajudar na assimilação dos assuntos da disciplina de química, as sugestões foram: Jogos com estrutura atômica = 10 alunos; Jogos com a tabela periódica $=$ 
28 alunos; Jogos com Ligações químicas = 20 alunos; Jogos com Funções inorgânicas = 9 alunos. O que demostra o interesse destes na obtenção de maiores conhecimentos acerca destes conteúdos através da realização destas atividades.

Miranda (2001) propôs que, vários objetivos podem ser atingidos a partir da utilização dos jogos didáticos, como os relacionados à cognição (desenvolvimento da inteligência e da personalidade, fundamentais para a construção de conhecimentos); a afeição (desenvolvimento da sensibilidade e da estima e atuação no sentido de estreitar laços de amizade e afetividade); a socialização (simulação de vida em grupo); a motivação (envolvimento da ação do desafio e mobilização da curiosidade) e a criatividade. Sendo assim, pode-se dizer que os jogos didáticos ligados ao ensino constituem um importante recurso, para que o professor possa desenvolver habilidades importantes para o cotidiano escolar e social do discente (como, a habilidade de resolução de problemas, favorecendo assim, a formulação e a reformulação dos conceitos) atendendo assim, as características da adolescência.

\section{CONSIDERAÇÕES FINAIS}

Este trabalho possibilitou identificar alguns aspectos importantes que, direta e profundamente, estão relacionados ao desenvolvimento do processo de ensino e aprendizagem da disciplina de Ciências/Química no Nível Fundamental. A partir das respostas dadas por alunos ao questionário aplicado na etapa de trabalho de campo desta pesquisa, foi possível realizar algumas discussões e reflexões sobre as concepções, adquiridas por estudantes do nono ano de duas turmas ( $A$ e $B$ ) do Colégio
São Paulo na Cidade de Belém do Pará, a respeito do Ensino de Química.

Os resultados obtidos sugerem que os jogos educacionais atuam como ferramentas eficientes nos processos de ensino e aprendizagem da Química. Os jogos devem ser utilizados como ferramentas de apoio ao ensino e que este tipo de prática pedagógica conduz o estudante à exploração de sua criatividade, dando condições de uma melhora de conduta no processo de ensino e aprendizagem, além de uma melhoria de sua auto-estima. Assim, podemos concluir que o indivíduo criativo constitui um elemento importante para a construção de uma sociedade melhor, pois se torna capaz de fazer descobertas, inventar e, consequentemente, provocar mudanças.

O jogo de reações químicas foi confeccionado com materiais simples e acessíveis, o que torna ainda mais fácil a sua aplicação. Esse tipo de atividade apresenta um diferencial, frente a outras já conhecidas e difundidas no âmbito da comunidade de profissionais permitindo o desenvolvimento de competências no âmbito da comunicação, das relações interpessoais, da liderança e do trabalho em equipe e utilizando a relação cooperação em um contexto formativo, pois os alunos cooperam com os colegas de equipe, como uma forma de estimular a interação do individuo com a sociedade.

\section{REFERÊNCIAS}

BERTOSO, E. B. F.; MOTA, E. A. S. A Ludicidade no Ensino da Matemática na Educação Infantil. São Paulo, 2011.

CUNHA, M. B. da. Jogos no Ensino de Química: Considerações Teóricas para sua Utilização em Sala de Aula. Química Nova na Escola, São Paulo, v. 34, n. 2, p.92-98, maio 
2012.

FERNANDES, L.D.; FURQUIM, A.A.; BARANAUSKAS, M.C.C. Jogos no Computador e a Formação de Recursos Humanos na Indústria. In: VI Simpósio Brasileiro de Informática na Educação, 1995, Anais... Florianópolis, SC, 1995.

FERREIRA, E. A.; GODOI, T. R. A.; SILVA, L. G. M. da; SILVA, T. P. da; ALBUQUERQUE, A. V. de. Aplicação de jogos lúdicos para o ensino de química: auxilio nas aulas sobre tabela periódica. In: Encontro Nacional de Educação, Ciência e Tecnologia UEPB, 1., 2012, Campina Grande. Anais do Encontro Nacional de Educação, Ciência e Tecnologia UEPB (2012). Campina Grande: Realize Eventos e Editora, 2012. v. 1, p. 1 - 10.

FIN, C. R. Um estudo sobre a utilização de objetos de aprendizagem computacionais voltados para o ensino da ortografia - ESPIE - CINTED - UFRGS, 2006.

FREIRE, J. B. Educação de corpo inteiro: teoria e prática da Educação Física. São Paulo: Scipione, 1997.

MARCELINO, N. C. Estudos do lazer: uma introdução. Campinas. São Paulo: Autores Associados, 1996.

PIAGET, J. A Linguagem e o Pensamento da Criança. São Paulo: Martins Fontes, 6a ed. 1993.

SCHWARTZ, G. M. O Processo Educacional em Jogo: Algumas Reflexões Sobre a Sublimação do Lúdico. Revista Licere/ Centro de Estudos de Lazer e Recreação/EEF/UFMG. v.1, n.1.Belo Horizonte,1998.

VIGOTSKY, L. S. A formação social da mente: o desenvolvimento dos processos psicológicos superiores/ organizadores Michael Cole... (et al.); tradução José Cipolla Neto, Luís Silveira Menna Barreto, Solange Castro Afeche. 7. ed. - São Paulo: Martins Fontes, 2007.
VYGOTSKY, L. S. O papel do brinquedo no desenvolvimento. In: A formação social da mente. São Paulo: Ed. Martins Fontes, 1989. p. 106-118.

\section{(c) (1) \\ License information: This is an open- access article distributed under the terms of the Creative Commons Attribution License, which permits unrestricted use, distribution, and reproduction in any medium, pro- vided the original work is properly cited.}

Artigo recebido em 10 de dezembro de 2016.

Avaliado em 26 de agosto de 2017.

Aceito em 11 de setembro de 2017.

Publicado em 22 de setembro de 2017.

\section{Como citar este artigo (ABNT):}

RÊGO, João Ricardo Souza do; CRUZ JUNIOR, Felipe Magno da; ARAÚJO, Maria Gabriella da Silva. Uso de jogos lúdicos no processo de ensino-aprendizagem nas aulas de Química. Estação Científica (UNIFAP), Macapá, v. 7, n. 2, p. 149-157, maio/ago. 2017. 